Zuzanna Michalak, PhD

Dima Obari, MSc

Matthew Ellis, PhD

Maria Thom, FRCPath

Sanjay M. Sisodiya,

FRCP, PhD

Correspondence to

Dr Sisodiya:

s.sisodiya@ucl.ac.uk
Supplemental data at Neurology.org

\title{
Neuropathology of SUDEP
}

\section{Role of inflammation, blood-brain barrier impairment, and hypoxia}

\section{OPEN}

\section{ABSTRACT}

Objective: To seek a neuropathologic signature of sudden unexpected death in epilepsy (SUDEP) in a postmortem cohort by use of immunohistochemistry for specific markers of inflammation, gliosis, acute neuronal injury due to hypoxia, and blood-brain barrier (BBB) disruption, enabling the generation of hypotheses about potential mechanisms of death in SUDEP.

Methods: Using immunohistochemistry, we investigated the expression of 6 markers (CD163, human leukocyte antigen-antigen D related, glial fibrillary acid protein, hypoxia-inducible factor-1 $\alpha$ [HIF-1 $]$, immunoglobulin $G$, and albumin) in the hippocampus, amygdala, and medulla in 58 postmortem cases: 28 SUDEP (definite and probable), 12 epilepsy controls, and 18 nonepileptic sudden death controls. A semiquantitative measure of immunoreactivity was scored for all markers used, and quantitative image analysis was carried out for selected markers.

Results: Immunoreactivity was observed for all markers used within all studied brain regions and groups. Immunoreactivity for inflammatory reaction, BBB leakage, and HIF-1 $\alpha$ in SUDEP cases was not different from that seen in control groups.

Conclusions: This study represents a starting point to explore by immunohistochemistry the mechanisms underlying SUDEP in human brain tissue. Our approach highlights the potential and importance of considering immunohistochemical analysis to help identify biomarkers of SUDEP. Our results suggest that with the markers used, there is no clear immunohistochemical signature of SUDEP in human brain. Neurology ${ }^{\circledR} 2017 ; 88: 551-561$

\section{GLOSSARY}

BBB $=$ blood-brain barrier; GFAP $=$ glial fibrillary acid protein; HIF-1 $\boldsymbol{\alpha}=$ hypoxia-inducible factor-1 $\alpha$; HLA-DR $=$ human leukocyte antigen-antigen $\mathrm{D}$ related; $\mathbf{I g G}=$ immunoglobulin $\mathrm{G} ; \mathbf{I O}=$ inferior olive; $\mathbf{N E S D}=$ nonepileptic sudden death; PH-G = parahippocampal gyrus; SUDEP = sudden unexpected death in epilepsy; UCL = University College London; VLM = ventrolateral medulla.

Sudden unexpected death in epilepsy (SUDEP) is the major cause of epilepsy-related deaths. ${ }^{1}$ The cause of SUDEP is likely to be multifactorial, with evidence for genetic susceptibility ${ }^{2,3}$ and preterminal cardiac, respiratory, and autonomic mechanisms. ${ }^{4,5}$

The tissue basis of SUDEP is unknown, with only a limited number of neuropathologic studies. ${ }^{6}$ Sudden infant death syndrome and sudden unexplained death in childhood share with SUDEP common characteristics, including incidence, sleep-associated death, prone position at death, and history of febrile seizures. ${ }^{7,8}$ More detailed neuropathologic studies have shed some light on the mechanisms underlying these conditions. Abnormal astrogliosis in the medulla and gross asymmetry or microscopic anomalies in the hippocampus have been reported in sudden infant death syndrome. ${ }^{7,9-12}$ MRI studies in SUDEP have highlighted hippocampal volume asymmetries ${ }^{13}$ and atrophic changes in the brainstem, ${ }^{14}$

From the Department of Clinical and Experimental Epilepsy (Z.M., D.O., M.T., S.M.S.), University College London, and Department of Neuropathology (Z.M., D.O., M.E., M.T.), Institute of Neurology and National Hospital for Neurology and Neurosurgery, London, UK; and Epilepsy Society (S.M.S.), Chalfont St. Peter, Bucks, UK.

Go to Neurology.org for full disclosures. Funding information and disclosures deemed relevant by the authors, if any, are provided at the end of the article. The Article Processing Charge was paid by the authors.

This is an open access article distributed under the terms of the Creative Commons Attribution-NonCommercial-NoDerivatives License 4.0 (CC BY-NC-ND), which permits downloading and sharing the work provided it is properly cited. The work cannot be changed in any way or used commercially without permission from the journal. 
Table 1 Clinical and pathology data of individual cases

\begin{tabular}{|c|c|c|c|c|}
\hline Case & PM no. & $\begin{array}{l}\text { Sex/age at } \\
\text { death, } y\end{array}$ & $\begin{array}{l}\text { Age at onset of } \\
\text { epilepsy/duration, y }\end{array}$ & Epilepsy type \\
\hline \multicolumn{5}{|c|}{ SUDEP, definite } \\
\hline 1 & EP271 & $\mathrm{M} / 40$ & $36 / 4$ & Epilepsy related to alcohol abuse \\
\hline 2 & EP266 & $M / 38$ & $7 / 31$ & $\begin{array}{l}\text { Focal (temporal) lobe epilepsy of } \\
\text { unknown cause }\end{array}$ \\
\hline 3 & NA & $F / 18$ & $16 / 2$ & Unclassified \\
\hline 4 & NA & $M / 53$ & Unknown & $\begin{array}{l}\text { Unclassified. Left-sided HS and } \\
\text { contusions found at postmortem }\end{array}$ \\
\hline 5 & NA & $F / 27$ & $0.75 / 26$ & $\begin{array}{l}\text { Unclassified. Left-sided HS found } \\
\text { at postmortem }\end{array}$ \\
\hline 6 & NA & $\mathrm{M} / 19$ & Long term & $\begin{array}{l}\text { Unknown. No lesion identified on } \\
\text { neuropathology }\end{array}$ \\
\hline 7 & NA & $\mathrm{M} / 42$ & 11/31 & $\begin{array}{l}\text { Focal structural, old surgical scar } \\
\text { from treated brain abscess }\end{array}$ \\
\hline 8 & NA & $\mathrm{F} / 58$ & $47 / 11$ & $\begin{array}{l}\text { Structural-metabolic } \\
\text { (hemimegalencephaly) }\end{array}$ \\
\hline 9 & NA & $\mathrm{M} / 41$ & Unknown & Unclassified \\
\hline 10 & NA & $M / 69$ & $54 / 15$ & Unclassified \\
\hline 11 & NA & $\mathrm{F} / 17$ & $4 / 13$ & $\begin{array}{l}\text { Unclassified. Febrile convulsions } \\
\text { as child }\end{array}$ \\
\hline 12 & NA & $\mathrm{F} / 44$ & $5 / 39$ & Unclassified \\
\hline 13 & NA & $F / 33$ & Unknown & Unclassified \\
\hline 14 & EP253 & $\mathrm{M} / 40$ & Unknown & Unknown \\
\hline
\end{tabular}

Mode of death

Brain region present

NA H, M

NA

A, H, M

NA

A, H, M

NA

$\mathrm{H}, \mathrm{M}$

NA

H, M

NA

A, $\mathrm{H}, \mathrm{M}$

NA

$H, M$

NA

$\mathrm{H}, \mathrm{M}$

NA

$\mathrm{H}, \mathrm{M}$

NA

A, $\mathrm{H}, \mathrm{M}$

NA

A, $\mathrm{H}, \mathrm{M}$

NA

$H, M$

NA

A, $\mathrm{H}, \mathrm{M}$

NA

$\mathrm{H}$

SUDEP, probable

$\begin{array}{llll}15 & \text { EP067 } & \mathrm{F} / 45 & 14 / 31 \\ 16 & \text { EP099 } & \mathrm{M} / 47 & 1.5 / 46 \\ 17 & \text { EP088 } & \mathrm{F} / 40 & 8 / 32 \\ 18 & \text { EP130 } & \mathrm{F} / 19 & 1.2 / 18 \\ 19 & \text { EP219 } & \mathrm{F} / 27 & \text { Unknown } \\ 20 & \text { EP240 } & \mathrm{F} / 37 & 4 / 32 \\ 21 & \text { EP252 } & \mathrm{M} / 21 & \text { Unknown } \\ 22 & \text { EP290 } & \mathrm{F} / 48 & 0.5 / 47 \\ 23 & \text { EP286 } & \mathrm{M} / 31 & \text { Unknown } \\ 24 & \mathrm{NA} & \mathrm{M} / 26 & \text { Unknown } \\ 25 & \text { EP210 } & \mathrm{M} / 49 & 12 / 37 \\ 26 & \text { EP304 } & \mathrm{M} / 50 & 11 / 39 \\ 27 & \text { EP296 } & \mathrm{M} / 49 & 4 / 45 \\ 28 & \text { EP262 } & \mathrm{F} / 40 & 8 / 32\end{array}$

28

Epilepsy without SUDEP control

$\begin{array}{lllll}29 & \text { EP102 } & \text { M/82 } & 5 / 51 & \text { Focal epilepsy of unknown cause } \\ 30 & \text { EP133 } & \text { F/51 } & 22 / 29 & \text { Structural-metabolic } \\ \text { 31 } & \text { EP039 } & \text { F/46 } & 0.25 / 45 & \text { Focal epilepsy of unknown cause } \\ 32 & \text { EP047 } & \text { M/60 } & 3 / 57 & \text { Focal epilepsy of unknown cause } \\ 33 & \text { EP213 } & \text { M/66 } & 1 / 65 & \text { Dravet syndrome } \\ 34 & \text { EP031 } & \text { M/44 } & 7 / 37 & \text { Unclassified } \\ 35 & \text { EP135 } & \text { M/83 } & 3 / 77 & \text { Focal epilepsy of unknown cause }\end{array}$

$\begin{array}{ll}\text { NA } & \text { A, H, M } \\ \text { NA } & \text { M } \\ \text { NA } & \text { A, H, M } \\ \text { NA } & \text { A, H, M } \\ \text { NA } & \text { A, H } \\ \text { NA } & \text { H, M } \\ \text { NA } & \text { A, H, M } \\ \text { NA } & \text { A, H, M } \\ \text { NA } & \text { A, M } \\ \text { NA } & \text { H, M } \\ \text { NA } & H, M \\ \text { NA } & \text { A, H } \\ \text { NA } & \text { A } \\ \text { NA } & \text { A, H }\end{array}$

\section{Bronchopneumonia}

H, M

Metabolic derangement, possibly secondary to pneumonia

$\begin{array}{ll}\text { Bronchopneumonia } & \text { A } \\ \text { Pulmonary edema } & \text { A } \\ \text { Bronchopneumonia } & \text { A } \\ \text { Pulmonary edema } & \text { H, M } \\ \text { Pulmonary embolism } & \text { A, H, M }\end{array}$

Continued 
Table 1 Continued

\begin{tabular}{|c|c|c|c|c|c|c|}
\hline Case & PM no. & $\begin{array}{l}\text { Sex/age at } \\
\text { death, } y\end{array}$ & $\begin{array}{l}\text { Age at onset of } \\
\text { epilepsy/duration, } y\end{array}$ & Epilepsy type & Mode of death & $\begin{array}{l}\text { Brain region } \\
\text { present }\end{array}$ \\
\hline 36 & EP154 & $\mathrm{M} / 77$ & $5 / 72$ & Focal epilepsy of unknown cause & Bronchopneumonia & $\mathrm{A}, \mathrm{H}, \mathrm{M}$ \\
\hline 37 & EP196 & $\mathrm{M} / 84$ & $16 / 64$ & Unclassified & Bronchopneumonia & $A$ \\
\hline 38 & EP236 & $\mathrm{M} / 74$ & $14 / 50$ & Focal epilepsy of unknown cause & $\begin{array}{l}\text { Adenocarcinoma of the bowel } \\
\text { with metastasis }\end{array}$ & A \\
\hline 39 & EP188 & $M / 86$ & $14 / 72$ & Structural-metabolic & Bronchopneumonia/lung cancer & A \\
\hline \multicolumn{7}{|c|}{ NESD control } \\
\hline 41 & NA & M/75 & NA & NA & Myocardial infarct & $\mathrm{H}, \mathrm{M}$ \\
\hline 42 & NA & $F / 35$ & NA & NA & Cardiac arrest & $\mathrm{H}, \mathrm{M}$ \\
\hline 43 & NA & $\mathrm{F} / 85$ & NA & NA & Bilateral pulmonary embolism & A \\
\hline 46 & SD028-08 & $\mathrm{F} / 44$ & NA & NA & $\begin{array}{l}\text { Cardiovascular disease, } \\
\text { Marfan syndrome }\end{array}$ & $\mathrm{A}, \mathrm{H}, \mathrm{M}$ \\
\hline 47 & SD032-09 & $\mathrm{F} / 60$ & NA & NA & $\begin{array}{l}\text { Cardiovascular disease; } \\
\text { hypertensive heart disease }\end{array}$ & $\mathrm{A}, \mathrm{H}, \mathrm{M}$ \\
\hline 48 & SD006-10 & $F / 32$ & NA & NA & $\begin{array}{l}\text { Cardiovascular disease; } \\
\text { Marfan syndrome }\end{array}$ & $A, M$ \\
\hline 49 & SD018-11 & $\mathrm{F} / 50$ & NA & NA & Peritonitis; bowel infarction & $\mathrm{A}, \mathrm{H}, \mathrm{M}$ \\
\hline 50 & SD029-11 & $\mathrm{F} / 42$ & NA & NA & $\begin{array}{l}\text { Bronchial asthma; pulmonary } \\
\text { congestion }\end{array}$ & $A, H, M$ \\
\hline 51 & SD023-12 & $\mathrm{F} / 50$ & NA & NA & $\begin{array}{l}\text { Bronchial asthma; pulmonary } \\
\text { congestion }\end{array}$ & $\mathrm{H}, \mathrm{M}$ \\
\hline 56 & SD049-12 & $\mathrm{M} / 60$ & NA & NA & $\begin{array}{l}\text { Ischemic and hypertensive } \\
\text { heart disease }\end{array}$ & $\mathrm{A}, \mathrm{H}, \mathrm{M}$ \\
\hline 57 & NA & $F / 38$ & NA & NA & Cardiorespiratory failure & $\mathrm{A}, \mathrm{H}$ \\
\hline 58 & NA & $M / 29$ & NA & NA & Hypertrophic cardiomyopathy & $\mathrm{H}, \mathrm{M}$ \\
\hline
\end{tabular}

Abbreviations: $\mathrm{A}=$ amygdala; $\mathrm{H}$ = hippocampus; $\mathrm{HS}=$ hippocampal sclerosis; $\mathrm{M}$ = medulla; $\mathrm{NA}=$ not applicable; $\mathrm{NESD}=$ nonepileptic sudden death; $\mathrm{PM}=$ postmortem; SUDEP = sudden unexpected death in epilepsy.

For unclassified, determination was not possible from available data; for unknown, no data were available for determination.

warranting neuropathologic corroboration. Seizures spreading into the amygdala, which is functionally connected to the medulla, may cause cessation of spontaneous breathing. ${ }^{15}$ Focal neuronal loss and gliosis have been described within amygdaloid subnuclei in SUDEP. ${ }^{16}$

Seizures can damage the brain through hypoxic stress ${ }^{17,18}$ and alter blood-brain barrier (BBB) integrity ${ }^{19-21}$ and promote inflammatory processes ${ }^{22,23}$ through chronic or acute changes. Our aim was to identify possible neuropathologic signatures of SUDEP in 3 brain regions, the medulla, hippocampus, and amygdala, which might be considered specifically to "prime" the brain in epilepsy for SUDEP or to reflect its occurrence. We investigated neuropathologic changes using commonly used markers of inflammation, gliosis, BBB disruption, and acute neuronal injury due to hypoxia in SUDEP, epilepsy, and nonepileptic sudden death (NESD) cases. This was an exploratory study of these processes in SUDEP intended 
Table 2 Primary antibodies and experimental conditions

\begin{tabular}{|c|c|c|c|c|c|c|c|}
\hline $\begin{array}{l}\text { Primary antibody } \\
\text { target }\end{array}$ & Source & $\begin{array}{l}\text { Clone or } \\
\text { reference }\end{array}$ & Supplier & Dilution & Incubation time & Pretreatment & Secondary antibody \\
\hline CD 163 & Mouse $\mathrm{mAb}$ & EDHu-1 & AbD Serotec, UK & $1 / 2,000$ & Overnight at $4^{\circ} \mathrm{C}$ & $\begin{array}{l}\text { HIER, Tris-based buffer, } \\
\mathrm{pH} 9\end{array}$ & $\begin{array}{l}\text { Universal anti-mouse/ } \\
\text { rabbit HRP (DAKO } \\
\text { Envision, UK) }\end{array}$ \\
\hline HLA-DR & Mouse mAb & $\mathrm{CR} 3 / 43$ & Dako, UK & $1 / 100$ & Overnight at $4^{\circ} \mathrm{C}$ & $\begin{array}{l}\text { HIER, Tris-based buffer, } \\
\text { pH } 9\end{array}$ & $\begin{array}{l}\text { Universal anti-mouse/ } \\
\text { rabbit HRP (DAKO } \\
\text { Envision) }\end{array}$ \\
\hline $\lg G$ & Rabbit pAb & $\mathrm{A} 0423$ & Dako, UK & $1 / 20,000$ & 60 min at RT & Proteinase $\mathrm{K}$ & $\begin{array}{l}\text { Universal anti-mouse/ } \\
\text { rabbit biotinylated } \\
\text { (VECTASTAIN, ABC } \\
\text { HRP kit, Vector, UK) }\end{array}$ \\
\hline Albumin & Rabbit pAb & A0001 & Dako, UK & $1 / 60,000$ & Overnight at $4^{\circ} \mathrm{C}$ & None & $\begin{array}{l}\text { Universal anti-mouse/ } \\
\text { rabbit HRP (DAKO } \\
\text { Envision) }\end{array}$ \\
\hline
\end{tabular}

Abbreviations: GFAP = glial fibrillary acid protein; HIER = heat-induced epitope retrieval; HIF- $1 \alpha=$ hypoxia-inducible factor- $1 \alpha ;$ HLA-DR $=$ human leukocyte antigen-antigen $\mathrm{D}$ related; $\mathrm{HRP}=$ horseradish peroxidase; IgG = immunoglobulin $\mathrm{G} ; \mathrm{mAb}=$ monoclonal antibody; $\mathrm{pAb}=$ polyclonal antibody; $\mathrm{RT}=$ room temperature.

to generate hypotheses for further testing in larger cohorts.

METHODS Standard protocol approvals, registrations, and patient consents. The project has been approved through National Research Ethics Service Committee South Central-Hampshire B reference 12/SC/0699. Tissue from all postmortem cases was retained with era-appropriate consent.

Case selection. All SUDEP and epilepsy cases were selected either from archives in the Epilepsy Society Brain and Tissue Bank, University College London (UCL) Institute of Neurology (London, UK) or via Brain UK (http://www. southampton.ac.uk/brainuk) from the pathology department at Derriford Hospital (Plymouth, UK). Cases were categorized according to a recent scheme $e^{24}$ on the basis of all available information, including detailed clinical and investigational data (e.g., MRI, EEG), and general postmortem findings, including organ histology and toxicology. NESD control tissues were obtained through the MRC Sudden Death Brain Bank, Edinburgh. We included 3 patient groups: SUDEP (definite and probable ${ }^{24}$ ), epilepsy controls, and NESD. From these cases, blocks were selected from the medulla, hippocampus, and amygdala (both sides when available). The clinical details and number of cases in each group are presented in table 1 .

Immunohistochemistry. Primary antibodies and experimental conditions are listed in table 2. Immunohistochemistry was performed on $5-\mu \mathrm{m}$-thick formalin-fixed paraffin-embedded sections. Endogenous peroxidase activity was blocked with 1\% hydrogen peroxide. The sections were incubated with primary antibodies in diluent buffer (Dako, UK Ltd, Ely, UK) followed by 30 minutes of incubation at room temperature with secondary antibodies. Immunocomplexes were visualized with Dako DAB+ Chromogen (Dako, Glostrup, Denmark). Sections were washed with phosphate-buffered saline (Fisher Scientific, Ltd,
Leicestershire, UK) between all steps. Negative controls were run simultaneously but without primary antibodies.

Semiquantitative evaluation (medulla, hippocampus, and amygdala). All sections were evaluated semiquantitatively twice by one observer (Z.M. or D.O.) and independently reviewed in $10 \%$ of cases by a second observer (M.T. or Z.M.). In the medulla, 6 regions of interest on the left and right sides were identified, 4 with known autonomic/cardiorespiratory regulatory functions: (1) floor of the fourth ventricle containing the dorsal nucleus of the vagus nerve and the 10th and 12th cranial nerve nuclei, (2) solitary tract, (3) arcuate nucleus, and (4) ventrolateral medulla (VLM) containing the pre-Bötzinger complex and nucleus ambiguus. In addition, 2 control medullary regions, (5) the inferior olives (IOs), and (6) pyramidal tracts were included. These easily identified regions were used with the rationale that if there were any "global" premortem insult involving the brainstem (e.g., hypoxia, infection), molecules such as hypoxia-inducible factor- $1 \alpha(\mathrm{HIF}-1 \alpha)$ and human leukocyte antigen-antigen D related (HLA-DR) would be more globally upregulated in control regions and in key autonomic-regulatory regions. In hippocampal sections, 8 regions of interest were studied: (1) dentate gyrus, (2) CA4, (3) CA3, (4) CA2, (5) CA1, (6) subiculum, (7) parahippocampal gyrus (PH-G), and (8) PH-G white matter. In the amygdala, 3 regions of interest were studied: (1) lateral nuclei, (2) basal nuclei, and (3) accessory basal nuclei. Grading scales for semiquantitative evaluation of immunoreactivity scores for all markers are detailed in appendix e-1 at Neurology.org.

Quantitative analysis. To supplement the semiquantitative data, quantitative evaluation of pathologic changes was carried out in the hippocampal sections stained for HLA-DR and in the amygdalar sections stained for glial fibrillary acid protein (GFAP). Slides were digitized with a whole slide scanner (LEICA SCN400 scanner, LEICA, Cambridge, UK) at $\times 40$ magnification. Definiens Tissue Studio 3.6 (Definiens AG, Munich, Germany) was used to outline the regions of interest on the scanned slides. Immunostaining was automatically 

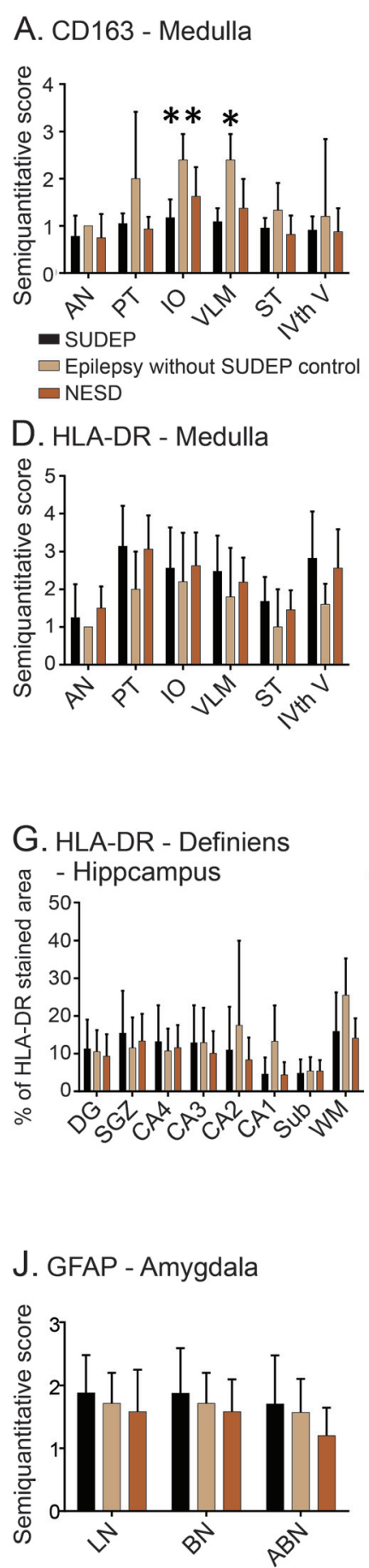
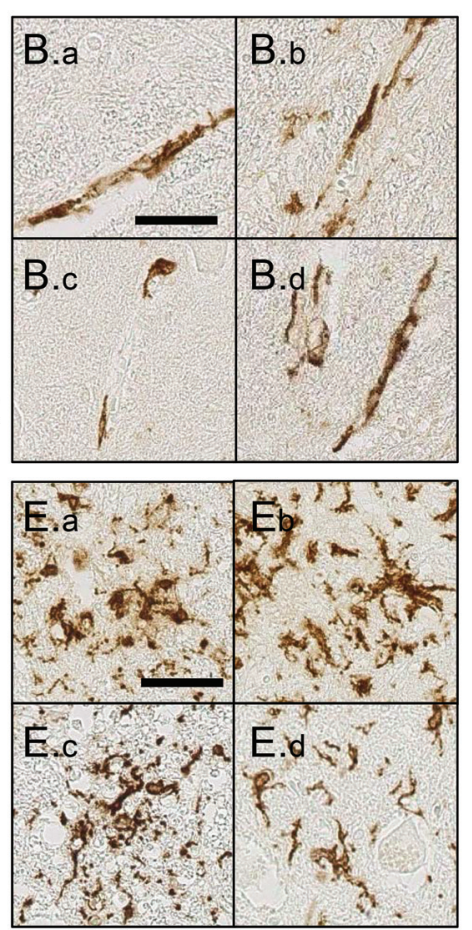

\section{F. HLA-DR - Hippocampus}

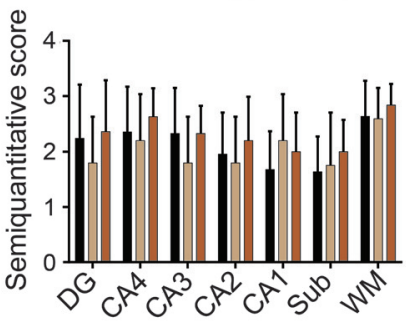

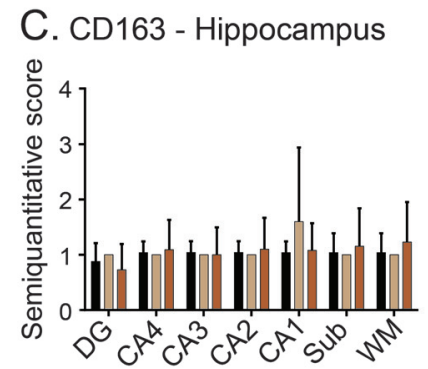
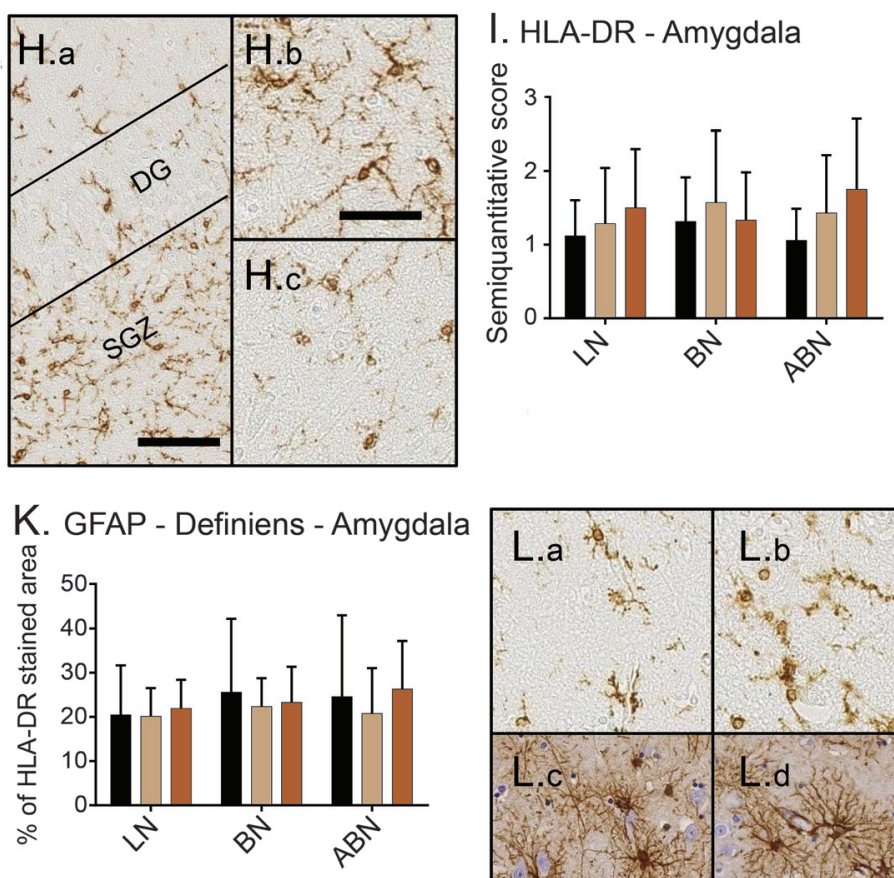

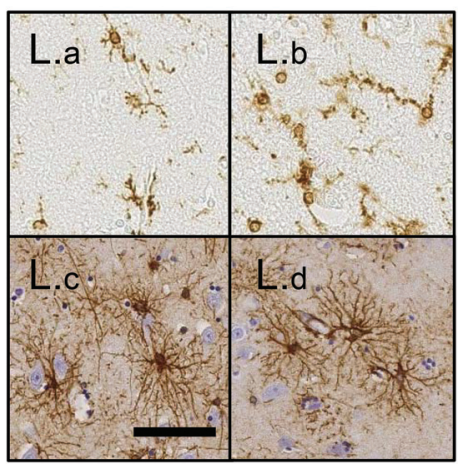

(A-C) Macrophage infiltration, (D-I) microglial activation, and (J-L) gliosis. (A) Semiquantitative evaluation of CD163 marker in the medulla. Expression of CD163 marker was significantly lower in sudden unexpected death in epilepsy (SUDEP) cases than in epilepsy without SUDEP controls in inferior olives (IOs) $(* * p<0.0005)$ and ventrolateral medulla (VLM; $* p \leq 0.001)$. (B) CD163-immunopositive perivascular macrophages are less frequent in a SUDEP case $(a, c)$ than in an epilepsy without SUDEP control (b, d) in both VLM (a-b) and IO (c-d) regions in the medulla. (C) Semiquantitative evaluation of CD163 marker in the hippocampus. (D) Semiquantitative evaluation of human leukocyte antigen-antigen D related (HLA-DR) marker in the medulla. (E) SUDEP case presenting high immunoreactivity for HLA-DR on microglial cells in medulla in the VLM (a), floor of the fourth ventricle (IVth V; b), pyramidal tracts (PT; c), and IOs (d). (F) Semiquantitative evaluation of HLA-DR marker in the hippocampus. (G) Quantitative evaluation of HLA-DR immunostaining in the hippocampus by Definiens software. (H) Hippocampus of a SUDEP case presenting higher immunostaining for HLA-DR in subgranular zone (SGZ; a) and in CA3 (b), with 
detected by Definiens software, which gave the percentage of the immunolabeled area in each region of interest. Details of threshold-based analysis of immunostaining by Definiens software are given in appendix e-1.

Statistical analysis and graphical representation. Statistical analysis was carried out with SPSS for windows (version 21, IBM Corp, Armonk, NY). GraphPad Prism software (version 6.1) was used for the graphic representation of the data. Nonparametric (Mann-Whitney $U$ ) tests were used to compare immunoreactivity scores between groups, and a stringent value of $p \leq 0.001$ was considered significant. We did not correct for multiple comparisons because this was a study intended to generate hypotheses.

RESULTS Inflammation. Immunoreactivity for CD163 (medulla, hippocampus), HLA-DR (medulla, hippocampus, amygdala), and GFAP (amygdala) was observed in all studied groups and regions of interest. Semiquantitative and quantitative (when applied) evaluation showed no difference overall between SUDEP cases and either control group in the immunoreactivity score, except for CD163 marker, which in VLM and IOs in SUDEP cases labeled fewer perivascular or parenchymal macrophages than in the epilepsy control group $(p<0.0005$ and $p \leq 0.001$, respectively, figure 1 , $A$ and B). This differential pattern of staining was not observed when SUDEP cases were compared to the NESD group.

In the medulla and hippocampus, the expression of CD163 marker was observed mainly in perivascular macrophages (figure 1, A-C). HLA-DR was immunolabeled in cells of microglial morphology, sometimes aggregating into nodules. Particularly in the medulla, intense HLA-DR immunostaining was noted in the VLM, solitary tract, floor of the fourth ventricle, and pyramidal tracts (in SUDEP and NESD cases, figure 1, D and E). In the hippocampus in all studied groups, HLA-DR-immunopositive cells were numerous in the dentate gyrus (especially in the subgranular zone), in the CA3-CA4 subfields, and in the white matter (figure 1, F-H). Fewer immunoreactive cells were observed in the CA1 subfield and the subiculum. In the amygdala, HLA-DR immunolabeling demonstrated intense microglial staining in all studied groups and nuclei (figure 1I). In the amygdala, in both control groups, the HLA-DR immunolabeling appeared more widespread and intense than in SUDEP cases, but these observations were not supported by semiquantitative analysis.
GFAP-immunopositive astrocytes were numerous in all studied groups and amygdala subnuclei (figure 1, $\mathrm{J}-\mathrm{L}$ ) as either isolated cells with frequent multiple strongly labeled processes or patchy areas of gliosis.

BBB integrity. Immunoreactivity for immunoglobulin G (IgG; medulla, hippocampus, amygdala) and albumin (medulla, hippocampus) was observed in the cytoplasm of neurons, astrocytes, and small cells with the morphology of oligodendroglia in all studied groups and regions of interest, indicating a compromised $\mathrm{BBB}$. In the medulla and amygdala, there was no difference overall between SUDEP cases and either control group in the immunoreactivity score (figure 2, A-C, G, and H).

In the hippocampus, prominent immunolabeling of a proportion of pyramidal neurons and astroglial cells was observed for both markers in all studied groups and subfields (figure 2, D-F). The dentate granule cell layer showed a prominent mosaic-like pattern of labeling of neurons and dendritic processes (figure 2E, a and e). The only differences were noted in the CA1 subfield and PH-G, with lower IgG immunoreactivity observed in SUDEP cases compared to NESD controls (both $p \leq 0.001$, figure $2 \mathrm{E}, \mathrm{b}, \mathrm{f}-\mathrm{h})$.

Acute neuronal injury. No significant differences were noted between SUDEP cases and either control group in any studied regions of interest for HIF-1 $\alpha$ immunolabeling except for the hippocampus, where fewer HIF- $1 \alpha$-immunopositive cells were noted in PH-G in SUDEP cases and the epilepsy control group than in NESD controls (both $p \leq 0.001$, figure 3, C and D, e and $\mathrm{f}$ ).

In the medulla, positive cytoplasmic neuronal labeling and a perisomatic synaptic immunolabeling pattern in the surrounding neuropil were seen in all groups studied (figure 3A). A high intensity of staining was observed in the majority of cases in the VLM (figure $3 \mathrm{~B}, \mathrm{~b}$ and e) and in the dorsal nucleus of the vagus nerve in the floor of the fourth ventricle (figure $3 \mathrm{~B}, \mathrm{c}$ and $\mathrm{f}$ ). In comparison, the 12 th cranial nerve nucleus showed less intense or absent immunoreactivity (figure 3B, $\mathrm{d}$ and $\mathrm{g}$ ). There was also immunolabeling in the arcuate nucleus. The IO nuclei showed a prominent band-like immunoreactivity of the neuropil, but pyramidal and white matter tracts were not labeled.

Figure 1 legend, continued:

lower immunoreactivity in the CA1 (c). (I) Semiquantitative evaluation of HLA-DR immunostaining in the amygdala. (J) Semiquantitative evaluation of glial fibrillary acid protein (GFAP) immunostaining in the amygdala. (K) Quantitative evaluation of GFAP immunostaining in the amygdala by Definiens software. (L) HLA-DR-immunopositive microglial cells in lateral nuclei (LN) of the amygdala are less abundant in a SUDEP (a) than in a nonepileptic sudden death (NESD; b) case, but expression of GFAP-immunopositive astrocytes is not different in a SUDEP (c) and a NESD (b) case. Scale bar in B, E, H.b, H.c, L.a, L.b = $50 \mu \mathrm{m}$; in H.a, L.c, L.d = $100 \mu \mathrm{m}$. ABN = accessory basal nuclei; $\mathrm{AN}=$ arcuate nucleus; $\mathrm{BN}=$ basal nuclei; $\mathrm{DG}=$ dentate gyrus; $\mathrm{ST}=$ solitary tract; $\mathrm{Sub}=$ subiculum; $\mathrm{WM}=$ white matter. 

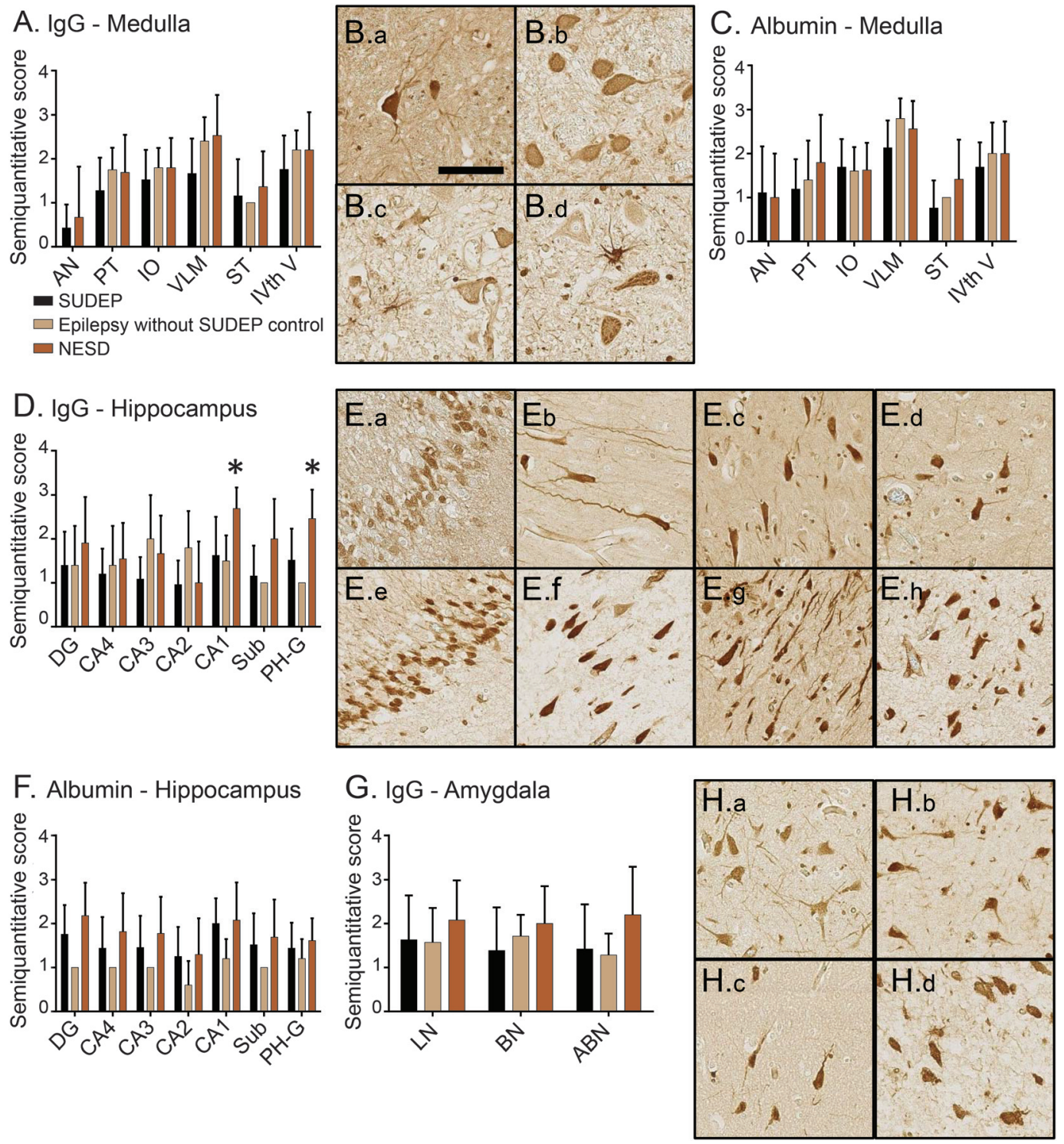

(A-C) Medulla, (D-F) hippocampus, and (G-H) amygdala. (A) Semiquantitative evaluation of immunoglobulin G (IgG) marker in the medulla. (B) Fewer IgG-immunopositive neurons and astrocytes were present in ventrolateral medulla (VLM; a) and the floor of the fourth ventricle (IVth $V ; c$ ) in a sudden unexpected death in epilepsy (SUDEP; b) than in a nonepileptic sudden death (NESD; d) case. (C) Semiquantitative evaluation of albumin marker in the medulla. (D) Semiquantitative evaluation of IgG marker in the hippocampus. Expression of IgG marker in SUDEP cases in CA1 and parahippocampal gyrus (PH-G ) was significantly lower than in NESD controls (*both $p \leq 0.001$ ). (E) Lower expression of IgG marker in the hippocampus of a SUDEP (a-d) than in a NESD (e-h) case in mosaic-like pattern of expression in the dentate gyrus (DG; a, e), pyramidal neurons in CA1 $(b, f)$, subiculum (Sub; $c, g)$ and PH-G (d, h). (F) Semiquantitative evaluation of albumin marker in the hippocampus. (G) Semiquantitative evaluation of IgG marker in the amygdala. (H) Fewer lgG-immunopositive cells were present in lateral nuclei (LN) in the SUDEP (a) than in the NESD (b) case and in accessory basal nuclei (ABN; $c$ and d, respectively). Scale bar for $\mathrm{B}, \mathrm{E}, \mathrm{H}=100 \mu \mathrm{m}$. $\mathrm{AN}$ = arcuate nucleus; $\mathrm{BBB}=$ blood-brain barrier; $\mathrm{BN}$ = basal nuclei; $\mathrm{IO}=$ inferior olive; $\mathrm{PT}=$ pyramidal tracts; $\mathrm{ST}=$ solitary tract.

In the hippocampus and amygdala, the pattern shared across the groups was of scattered cytoplasmic immunolabeling in single neurons in all subfields and nuclei (figure 3, C-F). Moreover, in the hippocampus, in SUDEP cases and NESD controls, a granular labeling pattern of staining was noted on fine processes at synapses within the dentate gyrus and molecular layer (figure 3D, $\mathrm{a}$ and $\mathrm{b}$ ) and within the pyramidal cell layer of CA2. Synaptic-like staining was also prominent in the layer II nodules in the subiculum (figure 3D, $c$ and d) and in all amygdaloid nuclei. The epilepsy control group did not show this prominent synaptic-like staining pattern.

DISCUSSION SUDEP is rare, but it is the most devastating outcome in epilepsy. A number of risk factors 
A. HIF-1 $\alpha$ - Medulla

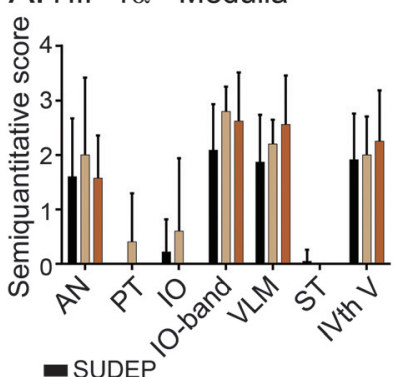

- SUDEP

$\square$ Epilepsy without SUDEP control $\square$ NESD
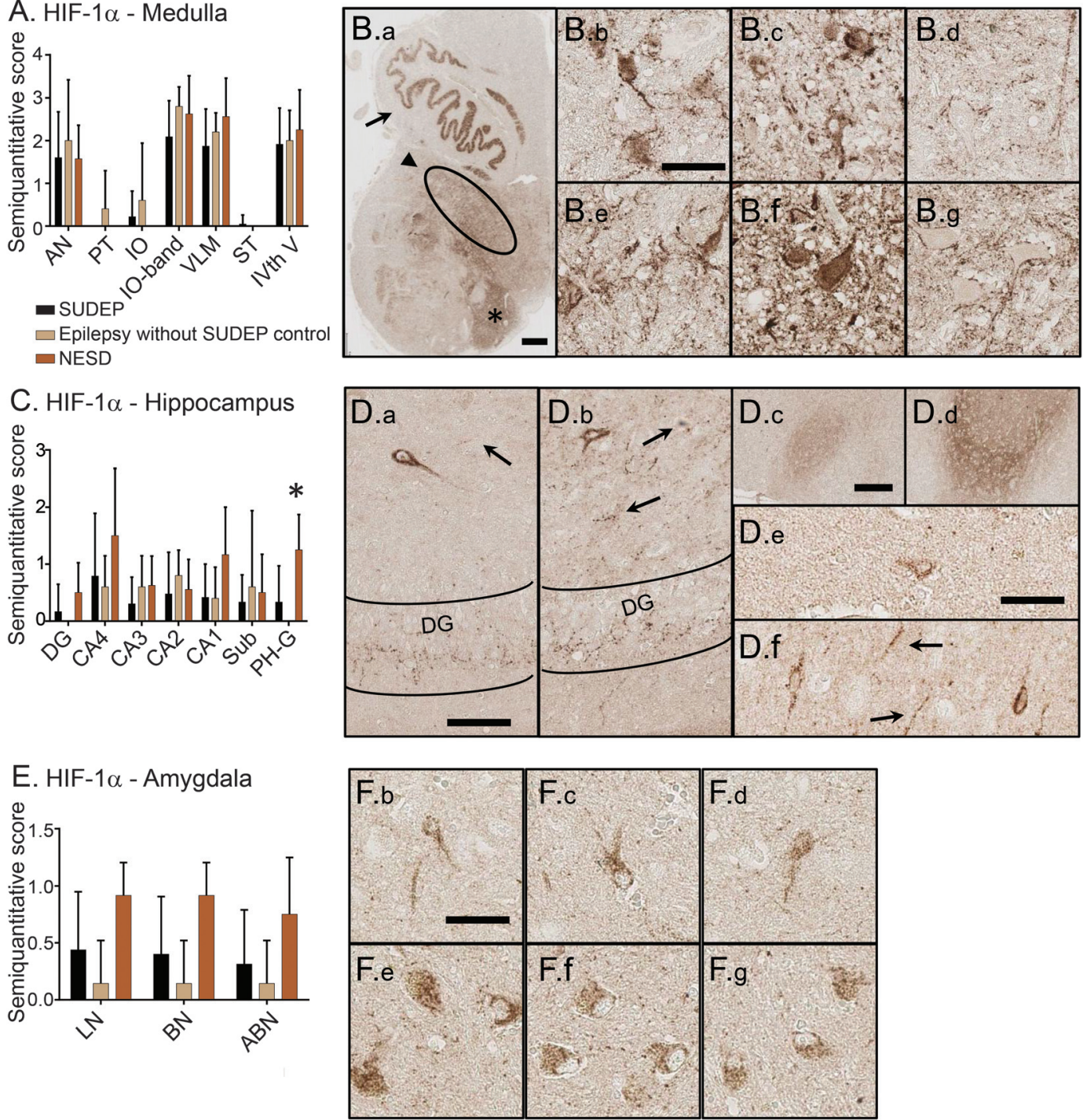

(A) Semiquantitative evaluation of hypoxia-inducible factor-1 $\alpha$ (HIF-1 $\alpha$ ) immunolabeling in the medulla. (B) HIF-1 $\alpha$ expression in the medulla of a sudden unexpected death in epilepsy (SUDEP) case (a) demonstrating band-like pattern in inferior olives (IOs; arrow) and strong immunolabeling in ventrolateral medulla (VLM; arrowhead) and floor of the fourth ventricle (IVth V) in the dorsal vagal nuclei (asterisk). Positive neurons in VLM $(b, e)$ and IVth V dorsal vagal nuclei $(c, f)$ were less frequent in a SUDEP case $(b, c)$ than in a NESD case (e, f). Absence of immunopositive neurons in IVth V 12th cranial nerve in both SUDEP (d) and NESD (g) cases. (C) Semiquantitative evaluation of HIF-1 $\alpha$ immunolabeling in the hippocampus. Expression of HIF-1 $\alpha$ marker in SUDEP cases in parahippocampal gyrus (PH-G) was significantly lower than in NESD controls (*p $\leq 0.001$ ). (D) HIF-1 $\alpha$ expression in the hippocampus demonstrating single immunopositive neurons and perisomatic immunolabeling (arrows) in the CA4 subfield and prominent synaptic-like staining in the dentate gyrus (DG) in a SUDEP (a) and a NESD (b) case. Less HIF-1 $\alpha$ immunolabeling in layer II nodules in the subiculum (Sub) in a SUDEP (c) than in a NESD (d) case. HIF-1 $\alpha$ expression in the PH-G presenting fewer immunopositive cells and perisomatic labeling (arrows) in SUDEP (e) than in NESD (f) case. (E) Semiquantitative evaluation of HIF-1 $\alpha$ immunolabeling in the amygdala. (F) HIF-1 $\alpha$ expression in the amygdala shows fewer immunopositive neurons in a SUDEP (a-c) than in a NESD (d-f) case in lateral nuclei $(L N ; a$, d), basal nuclei $(B N ; b, e)$, and accessory basal nuclei (ABN; $c$, f). Scale for $B . a=$ $1 \mathrm{~mm}$; B.b-B.g = $100 \mu \mathrm{m}$; D.a, D.b $=100 \mu \mathrm{m}$, D.c, D.d = $200 \mu \mathrm{m}$, D.e, D.f $=50 \mu \mathrm{m} ; \mathrm{F}=50 \mu \mathrm{m}$. AN = arcuate nucleus; PT = pyramidal tracts; ST solitary tract.

and terminal pathophysiologic phenomena have been determined. The cause remains unknown, although genetic factors may play a role. ${ }^{2,25}$ Associated acute neuropathologic alterations have been poorly investigated. We report a detailed analysis of postmortem brain tissue from people who have died of SUDEP, looking for acute cellular alterations in comparison to a variety of controls. With the markers used, there is limited evidence for a specific or stereotypical pathologic cellular reaction pattern occurring in people who have died of SUDEP in terms of inflammation, gliosis, BBB disruption, or acute neuronal injury due to 
hypoxia. The only significant differences were shown in the medulla for CD163 and in the hippocampus for IgG and HIF- $1 \alpha$ markers.

In the medulla, lower immunolabeling of CD163 was noted in VLM and IOs in SUDEP cases than in epilepsy controls, but these differences were not seen when SUDEP cases were compared to NESD controls. CNS macrophages are heterogeneous; resident microglia of myeloid lineage origins populate the CNS during embryonic development, while perivascular, meningeal, and choroid plexus macrophages of bone marrow origin are renewed from circulating monocytes. ${ }^{26}$ Perivascular macrophages are distinguished from microglia by expression of the CD163 marker. ${ }^{27}$ They occupy a strategic location at the BBB and have antigen recognition, processing, and presenting properties, supporting a possible role in the regulation of perivascular inflammation in the CNS. ${ }^{27}$ CD163-immunoreactive macrophages have been identified in the parenchyma in several inflammatory diseases such as HIV-related encephalitis, multiple sclerosis, and Alzheimer disease. ${ }^{27-29}$ The low expression of this marker observed in SUDEP would suggest as a hypothesis that acute macrophage-derived immunoreaction in the medulla is not important in SUDEP.

In the hippocampus, differences were noted in the PH-G, with lower IgG and HIF- $1 \alpha$ immunoreactivity, and in the CA1 subfield, with lower IgG immunoreactivity, in SUDEP cases compared to NESD controls. One of the consequences of BBB dysfunction is leakage of blood-borne cells into the brain. Indeed, a passive accumulation of various proteins could lead to aggregation, which perturbs neuronal function and survival. ${ }^{30,31} \mathrm{IgG}$ uptake has been associated with several signs of neuronal dysfunction. ${ }^{32}$ IgG binding may also be a response to the cell death. Such processes have been reported in aging brain. ${ }^{33}$ Moreover, in the injured brain, naturally occurring IgG autoantibodies have been shown to bind specifically to dying neurons and were suggested to promote phagocytosis and removal of injured neurons. ${ }^{31}$ Hypoxia changes several processes in neuronal physiology, ${ }^{34}$ many aspects of which involve HIF- $1 \alpha .{ }^{35} \mathrm{~A}$ small number of cells immunoreactive to HIF- $1 \alpha$ were recently reported in postmortem samples from patients with epilepsy. ${ }^{36} \mathrm{HIF}-1 \alpha$ has a relatively short half-life of only several minutes, and because it is rapidly degraded in normoxia, there is essentially no detectable level of HIF- $1 \alpha$ protein under these circumstances. ${ }^{37}$ Amongst NESD cases, 16 of 18 had documented hypoxic/ischemic conditions as a cause of death and presented intense HIF-1 $\alpha$ immunolabeling in all studied brain areas. Therefore, the findings of only occasional HIF- $1 \alpha$-immunopositive cells in SUDEP cases and lower IgG immunoreactivity suggest the relative lack of BBB impairment or hypoxia associated with SUDEP cases in this series compared to other sudden death cases. This leads to the hypothesis that prolonged impaired cerebral perfusion/oxygenation is not always a critical process in the mechanism of death in SUDEP. These observations may seem paradoxical given the recent finding from the MORTEMUS (Mortality in Epilepsy Monitoring Unit) study ${ }^{5}$ documenting terminal cardiorespiratory arrest in SUDEP. There are a number of possible reasons for our observations, including the possible heterogeneity of underlying causation in SUDEP whatever the terminal event, that hypoxia does not affect the whole brain to equal severity, or that there is reduced metabolic demand in tissue due to postictal generalized electric suppression. That HIF-1 $\alpha$ immunoreactivity is seen in NESD tissue argues against insensitivity of the assay as a technical explanation.

We qualitatively evaluated $\operatorname{IgG}$ and albumin immunoreactivity in overall cell populations (including neurons and astrocytes) without cell-specific distinction. However, it has been reported that parenchymal accumulation of albumin, particularly in astrocytes, induces downregulation of inwardrectifying Kir4.1 potassium channels and impairs gap junction coupling, leading to an increase in extracellular potassium level, precipitating epileptiform activity. ${ }^{38,39}$ High extracellular potassium and glutamate concentrations and severe hypoxia/anoxia can also trigger spreading depolarization. When spreading depolarization affects structures responsible for breathing control, it may worsen hypoxia, thus generating a vicious circle resulting in shutdown of cardiorespiratory centers and flattening of the EEG. ${ }^{40}$ Therefore, functional dysregulation of the neuronal, glial, and microvascular networks at the BBB may be of relevance in the pathophysiology of sudden death, and we suggest that this area needs further investigation.

There are limitations of our study. The circumstances of life, death, and postmortem conditions in humans often vary significantly between cases, in contrast to studies in animal models in which premortem and postmortem conditions can be controlled. We used a number of SUDEP and control cases collected over many years. Moreover, we also used tissue from other centers around the United Kingdom. In such studies, premortem and postmortem variations are inevitable, for example, with respect to postmortem intervals and tissue processing differences between centers and over time. The cohort used in the current study is not a systematically collected population-based sample and therefore may not be representative of all SUDEP. We had a limited number of controls in our study, especially epilepsy 
controls. Another potential limitation is the different tissue sampling between cases in that sections of medulla, hippocampus, and amygdala were not all at identical levels. However, we used adjacent sections stained with Luxol fast blue and cresyl violet to enable proper orientation of each section, and we examined only the sections in which each region of interest was entirely present. Another constraint is that not all 3 brain regions were available from each patient, which may have affected the comparison between the studied groups. We emphasize that our study was intended to generate hypotheses and that further work is needed. We examined a limited number of antigens, which may not represent all aspects of inflammation, BBB integrity, and hypoxic stress. We could not use most "omics" techniques because all material available in this study was fixed and embedded without details on premortem and agonal conditions. We are aware that use of omics techniques may provide information for a larger number of genes and gene products involved in mechanisms underlying pathology, which cannot be obtained with traditional techniques. However, cases of SUDEP with brain tissue available for research are very limited, and we attempted to make the most of the limited resources available. Finally, we note that none of our SUDEP cases were from acute monitoring units, so the immediate preterminal period was not electrophysiologically documented.

This study represents a starting point to explore the neuropathology and cellular alterations associated with SUDEP. We did not find any distinct pathognomonic brain processes to support activation of inflammatory, BBB impairment, or cell stress/hypoxia pathways. However, further investigation of the role of glioneuronal interactions and the BBB impairment may be worthwhile.

\section{AUTHOR CONTRIBUTIONS}

Zuzanna Michalak: study concept and design, acquisition, analysis and interpretation of data, study supervision, writing the manuscript. Dima Obari: acquisition, analysis and interpretation of data. Matthew Ellis: acquisition and analysis of data. Maria Thom and Sanjay M. Sisodiya: study concept and design, critical revision of manuscript for intellectual content.

\section{STUDY FUNDING}

The work was supported by a grant from CURE (Citizens United for Research in Epilepsy grant 249966) and funding from the European Union's Seventh Framework Program (FP7/2007-2013) under grant agreement 602102 (EPITARGET). SUDEP studies at UCL Hospitals/ UCL are supported by the Centre for SUDEP Research through the National Institute of Neurological Disorders and Stroke of the NIH under awards U01 NS090415. This work was undertaken at UCL and UCL Hospitals, which receive part of their funding from the Department of Health Biomedical Centre scheme. Tissues were provided by the Epilepsy Society Brain and Tissue Bank (UCL, Institute of Neurology, London, UK; supported though the Katy Baggott Foundation), Brain UK, and Dr. David Hilton at the Pathology Department at the Derriford Hospital (Plymouth, UK) and the MRC Edinburgh Brain Bank (Edinburgh, UK).

\section{DISCLOSURE}

The authors report no disclosures relevant to the manuscript. Go to Neurology.org for full disclosures.

Received May 19, 2016. Accepted in final form November 9, 2016.

\section{REFERENCES}

1. Walczak TS, Leppik IE, D'Amelio M, et al. Incidence and risk factors in sudden unexpected death in epilepsy: a prospective cohort study. Neurology 2001;56:519-525.

2. Leu C, Balestrini S, Maher B, et al. Genome-wide polygenic burden of rare deleterious variants in sudden unexpected death in epilepsy. eBioMedicine. 2015;2:1063-1070.

3. Sakauchi M, Oguni H, Kato I, et al. Retrospective multiinstitutional study of the prevalence of early death in Dravet syndrome. Epilepsia 2011;52:1144-1149.

4. Surges R, Thijs RD, Tan HL, Sander JW. Sudden unexpected death in epilepsy: risk factors and potential pathomechanisms. Nat Rev Neurol 2009;5:492-504.

5. Ryvlin P, Nashef L, Lhatoo SD, et al. Incidence and mechanisms of cardiorespiratory arrests in epilepsy monitoring units (MORTEMUS): a retrospective study. Lancet Neurol 2013;12:966-977.

6. Thom M, Michalak Z, Wright G, et al. Audit of practice in SUDEP post mortems and neuropathological findings. Neuropathol Appl Neurobiol 2015;24:12265.

7. Kinney HC, Chadwick AE, Crandall LA, et al. Sudden death, febrile seizures, and hippocampal and temporal lobe maldevelopment in toddlers: a new entity. Pediatr Dev Pathol 2009; 12:455-463.

8. Hesdorffer DC, Crandall LA, Friedman D, Devinsky O. Sudden unexplained death in childhood: a comparison of cases with and without a febrile seizure history. Epilepsia 2015;56:1294-1300.

9. Kinney HC, Cryan JB, Haynes RL, et al. Dentate gyrus abnormalities in sudden unexplained death in infants: morphological marker of underlying brain vulnerability. Acta Neuropathol 2015;129:65-80.

10. Naeye RL. Brain-stem and adrenal abnormalities in the sudden-infant-death syndrome. Am J Clin Pathol 1976; 66:526-530.

11. Kinney HC, Burger PC, Harrell FE Jr, Hudson RP Jr. "Reactive gliosis" in the medulla oblongata of victims of the sudden infant death syndrome. Pediatrics 1983;72:181-187.

12. Biondo B, Magagnin S, Bruni B, Cazzullo A, Tosi D, Matturri L. Glial and neuronal alterations in the nucleus tractus solitarii of sudden infant death syndrome victims. Acta Neuropathol 2004;108:309-318.

13. Wandschneider B, Koepp M, Scott C, et al. Structural imaging biomarkers of sudden unexpected death in epilepsy. Brain 2015;138:2907-2919.

14. Mueller SG, Bateman LM, Laxer KD. Evidence for brainstem network disruption in temporal lobe epilepsy and sudden unexplained death in epilepsy. Neuroimage Clin 2014;5:208-216.

15. Dlouhy BJ, Gehlbach BK, Kreple CJ, et al. Breathing inhibited when seizures spread to the amygdala and upon amygdala stimulation. J Neurosci 2015;35:10281-10289.

16. Thom M, Griffin B, Sander JW, Scaravilli F. Amygdala sclerosis in sudden and unexpected death in epilepsy. Epilepsy Res 1999;37:53-62.

17. Moseley BD, Nickels K, Britton J, Wirrell E. How common is ictal hypoxemia and bradycardia in children with partial complex and generalized convulsive seizures? Epilepsia 2010;51:1219-1224. 
18. Bateman LM, Li CS, Seyal M. Ictal hypoxemia in localization-related epilepsy: analysis of incidence, severity and risk factors. Brain 2008;131:3239-3245.

19. Rigau V, Morin M, Rousset MC, et al. Angiogenesis is associated with blood-brain barrier permeability in temporal lobe epilepsy. Brain 2007;130:1942-1956.

20. Michalak Z, Lebrun A, Di Miceli M, et al. IgG leakage may contribute to neuronal dysfunction in drug-refractory epilepsies with blood-brain barrier disruption. J Neuropathol Exp Neurol 2012;71:826-838.

21. van Vliet EA, da Costa Araujo S, Redeker S, van Schaik R, Aronica E, Gorter JA. Blood-brain barrier leakage may lead to progression of temporal lobe epilepsy. Brain 2007;130: 521-534.

22. Aronica E, Crino PB. Inflammation in epilepsy: clinical observations. Epilepsia 2011;52(Suppl 3):26-32.

23. Vezzani A, French J, Bartfai T, Baram TZ. The role of inflammation in epilepsy. Nat Rev Neurol 2011;7:31-40.

24. Nashef L, So EL, Ryvlin P, Tomson T. Unifying the definitions of sudden unexpected death in epilepsy. Epilepsia 2012;53:227-233.

25. Bagnall RD, Crompton DE, Petrovski S, et al. Exomebased analysis of cardiac arrhythmia, respiratory control and epilepsy genes in sudden unexpected death in epilepsy. Ann Neurol 2016;79:522-534.

26. London A, Cohen M, Schwartz M. Microglia and monocyte-derived macrophages: functionally distinct populations that act in concert in CNS plasticity and repair. Front Cell Neurosci 2013;7:34.

27. Fabriek BO, Van Haastert ES, Galea I, et al. CD163positive perivascular macrophages in the human CNS express molecules for antigen recognition and presentation. Glia 2005;51:297-305.

28. Pey P, Pearce RK, Kalaitzakis ME, Griffin WS, Gentleman SM. Phenotypic profile of alternative activation marker CD163 is different in Alzheimer's and Parkinson's disease. Acta Neuropathol Commun 2014;2:21.

29. Roberts ES, Masliah E, Fox HS. CD163 identifies a unique population of ramified microglia in HIV encephalitis (HIVE). J Neuropathol Exp Neurol 2004;63:1255-1264.

30. Loberg EM, Karlsson BR, Torvik A. Neuronal uptake of plasma proteins after transient cerebral ischemia/hypoxia. Immunohistochemical studies on experimental animals and human brains. APMIS 1993;101:777-783.

31. Stein TD, Fedynyshyn JP, Kalil RE. Circulating autoantibodies recognize and bind dying neurons following injury to the brain. J Neuropathol Exp Neurol 2002;61:1100-1108.

32. Garman RH. Histology of the central nervous system. Toxicol Pathol 2011;39:22-35.

33. Boren E, Gershwin ME. Inflamm-aging: autoimmunity, and the immune-risk phenotype. Autoimmun Rev 2004;3: 401-406.

34. Chao D, Xia Y. Ionic storm in hypoxic/ischemic stress: can opioid receptors subside it? Prog Neurobiol 2010; 90:439-470.

35. Ebert BL, Firth JD, Ratcliffe PJ. Hypoxia and mitochondrial inhibitors regulate expression of glucose transporter-1 via distinct Cis-acting sequences. J Biol Chem 1995;270: 29083-29089.

36. Feast A, Martinian L, Liu J, Catarino CB, Thom M, Sisodiya SM. Investigation of hypoxia-inducible factor1alpha in hippocampal sclerosis: a postmortem study. Epilepsia 2012;53:1349-1359.

37. Wang GL, Jiang BH, Rue EA, Semenza GL. Hypoxiainducible factor 1 is a basic-helix-loop-helix-PAS heterodimer regulated by cellular $\mathrm{O} 2$ tension. Proc Natl Acad Sci USA 1995;92:5510-5514.

38. Ivens S, Kaufer D, Flores LP, et al. TGF-beta receptormediated albumin uptake into astrocytes is involved in neocortical epileptogenesis. Brain 2007;130:535-547.

39. Braganza $\mathrm{O}$, Bedner P, Huttmann $\mathrm{K}$, et al. Albumin is taken up by hippocampal NG2 cells and astrocytes and decreases gap junction coupling. Epilepsia 2012;53: 1898-1906.

40. Somjen GG. Mechanisms of spreading depression and hypoxic spreading depression-like depolarization. Physiol Rev 2001;81:1065-1096.

\section{Neuro Film Festival Accepting Videos-4 chances to win $\$ 1,000$ !}

Submit a video into one of four festival categories that best suits your story about brain disease, and help build awareness of the importance of neuroscience research for patients and the physicians and scientists who treat and work to find cures.

1. "Why I think Neuroscience Is... ${ }^{\mathrm{TM}}$ Cool"-Tell us why the brain is fascinating

2. "Why I think Neuroscience Is... ${ }^{\text {TM }}$ Rewarding"-Tell us how discovery opens doors

3. "Why I think Neuroscience Is... ${ }^{\text {TM }}$ Essential"-Tell us why research is important

4. "Why I think Neuroscience Is... ${ }^{\text {TM }}$ Critical"-Tell us why advocacy makes an impact

Submission deadline: March 10, 2017.

Visit NeuroFilmFestival.com for complete contest rules, idea tips, and submission instructions. 


\section{Neurology}

\section{Neuropathology of SUDEP: Role of inflammation, blood-brain barrier impairment, and hypoxia}

Zuzanna Michalak, Dima Obari, Matthew Ellis, et al. Neurology 2017;88;551-561 Published Online before print January 13, 2017

DOI 10.1212/WNL.0000000000003584

\section{This information is current as of January 13, 2017}

\section{Updated Information \& Services}

Supplementary Material

\section{References}

Citations

Subspecialty Collections

Permissions \& Licensing

Reprints including high resolution figures, can be found at: http://n.neurology.org/content/88/6/551.full

Supplementary material can be found at: http://n.neurology.org/content/suppl/2017/01/13/WNL.0000000000003 584.DC1

http://n.neurology.org/content/suppl/2018/03/27/WNL.0000000000003 584.DC2

This article cites 40 articles, 4 of which you can access for free at: http://n.neurology.org/content/88/6/551.full\#ref-list-1

This article has been cited by 3 HighWire-hosted articles: http://n.neurology.org/content/88/6/551.full\#\#otherarticles

This article, along with others on similar topics, appears in the following collection(s):

All Epilepsy/Seizures

http://n.neurology.org/cgi/collection/all_epilepsy_seizures

Information about reproducing this article in parts (figures,tables) or in its entirety can be found online at:

http://www.neurology.org/about/about_the_journal\#permissions

Information about ordering reprints can be found online: http://n.neurology.org/subscribers/advertise

Neurology ${ }^{\circledR}$ is the official journal of the American Academy of Neurology. Published continuously since 1951, it is now a weekly with 48 issues per year. Copyright Copyright ( 2017 The Author(s). Published by Wolters Kluwer Health, Inc. on behalf of the American Academy of Neurology. All rights reserved. Print ISSN: 0028-3878. Online ISSN: 1526-632X.

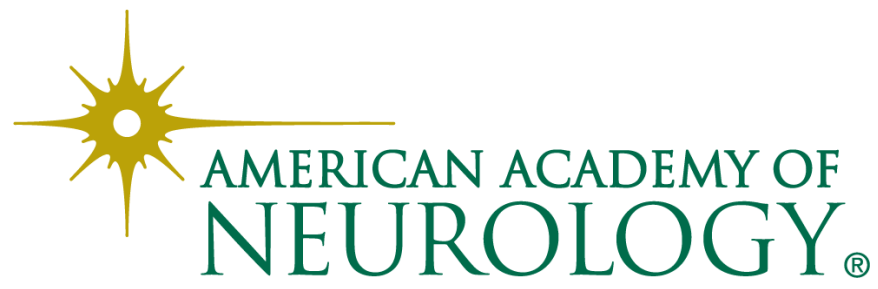

